\title{
Oceanic Forcing on Interannual Variability of Sahel Heavy and Moderate Daily Rainfall
}

\author{
M. DiAKHATÉ \\ Laboratoire de Physique de l'Atmosphère et de l'Océan-Siméon Fongang, Ecole Supérieure Polytechnique, \\ Université Cheikh Anta Diop, Dakar, Senegal \\ B. RODRÍGUEZ-FONSECA \\ Departamento de Física de la Tierra y Astrofísica, Universidad Complutense de Madrid, and Instituto de Geociencias, \\ Universidad Complutense de Madrid-Consejo Superior de Investigaciones Científicas, Madrid, Spain \\ I. GÓMARA \\ CEIGRAM, and Departamento de Producción Agraria, Universidad Politécnica de Madrid, Madrid, Spain \\ E. MOHINO \\ Departamento de Física de la Tierra y Astrofísica, Universidad Complutense de Madrid, Madrid, Spain \\ A. L. Dieng And A. T. GAYE \\ Laboratoire de Physique de l'Atmosphère et de l'Océan-Siméon Fongang, Ecole Supérieure Polytechnique, \\ Université Cheikh Anta Diop, Dakar, Senegal
}

(Manuscript received 17 February 2018, in final form 18 October 2018)

\begin{abstract}
This article analyzes SST remote forcing on the interannual variability of Sahel summer (June-September) moderate (below 75th percentile) and heavy (above 75th percentile) daily precipitation events during the period 1981-2016. Evidence is given that interannual variability of these events is markedly different. The occurrence of moderate daily rainfall events appears to be enhanced by positive SST anomalies over the tropical North Atlantic and Mediterranean, which act to increase low-level moisture advection toward the Sahel from the equatorial and north tropical Atlantic (the opposite holds for negative SSTs anomalies). In contrast, heavy and extreme daily rainfall events seem to be linked to El Niño-Southern Oscillation (ENSO) and Mediterranean variability. Under La Niña conditions and a warmer Mediterranean, vertical atmospheric instability is increased over the Sahel and low-level moisture supply from the equatorial Atlantic is enhanced over the area (the reverse is found for opposite-sign SST anomalies). Further evidence suggests that interannual variability of Sahel rainfall is mainly dominated by the extreme events. These results have implications for seasonal forecasting of Sahel moderate and heavy precipitation events based on SST predictors, as significant predictability is found from 1 to 4 months in advance.
\end{abstract}

\section{Introduction}

The Sahel is facing an increase of extreme rainfall occurrence (Ly et al. 2013). Recently, Taylor et al. (2017) have shown that extreme thunderstorms over the Sahel are nowadays 3 times more frequent than they

Corresponding author: Moussa Diakhaté, moussa1.diakhate@ ucad.edu.sn were 35 years ago. These extremes constitute the primary impact of climate change on society (Katz and Brown 1992), more than changes in the mean climate (Mitchell et al. 1990). Due to the vulnerability of the Sahel region, precipitation extremes often directly (and indirectly) impact numerous economy sectors and are associated with elevated death tolls (New et al. 2006; Lobell et al. 2011; Anyamba et al. 2014; Sané et al. 2015, 2016). The predictability of these extreme events is a big 
challenge for the climate science community in the Sahel area.

Among processes controlling Sahel rainfall variability, oceanic forcing has been found to be the dominant driver (Giannini et al. 2003; Rowell 2013; RodríguezFonseca et al. 2011, 2015; Gómara et al. 2018). Many works have shown that seasonal rainfall variability over the Sahel is related to sea surface temperature (SST) anomalies over the tropical Atlantic, Pacific, and the Mediterranean Sea (Rodríguez-Fonseca et al. 2015, and references therein). In particular, a warming of Pacific and Atlantic tropical waters has been found to promote a decrease in seasonal Sahelian rainfall (e.g., Rowell 2001; Janicot et al. 2001; Mohino et al. 2011a,b; Losada et al. 2010), while a warmer Mediterranean leads to an increase (Rowell 2013; Fontaine et al. 2010). These relations are somewhat linear, as opposite responses in rainfall take place when colder-than-usual SSTs arise over the same marine regions.

Regarding Sahel daily rainfall intensity/frequency, Giannini et al. (2013) found that the recovery during the last two decades was accompanied by the relative predominance of an increase in median rainfall intensity. Such an increase was shown to coincide with positive SST anomalies over the tropical North Atlantic (TNA), potentially associated with a positive phase of the Atlantic multidecadal oscillation (AMO). Additionally, it was also shown that extreme dry spell occurrence over West Africa is significantly linked to anomalous SSTs in the Indian and South Atlantic oceans (Bader and Latif 2011; Salack et al. 2014). Parhi et al. (2016) also revealed that El Niño-Southern Oscillation (ENSO) significantly influences the interannual variability of Sahel rainy days frequency during boreal summer.

In contrast, the possible influence of SST forcing on Sahel precipitation, stratified and isolated in terms of event intensity (e.g., moderate, extreme), has received little attention in the literature so far. Ta et al. (2016) recently endeavored this subject, but their analysis focused on tropical Atlantic SST forcing over the Sahelian and Guinean regions, and they looked for oceanic forcing associated with trends on extreme rainfall. Results from this study pointed out the existence of a significant link between extreme rainfall trends over West Africa and SST anomalies in the equatorial Atlantic.

Distinctively, the present paper focuses on the interannual variability of Sahel rainfall events of different intensities (e.g., low, moderate, heavy, and extreme), searching for oceanic sources of predictability worldwide to provide skillful seasonal forecasts. The article is structured as follows. Section 2 describes the data and methodology used. Section 3 is centered in the analysis of Sahel moderate and heavy precipitation indices, their associated teleconnections and mechanisms, and their seasonal predictability. A summary of the main findings concludes this article.

\section{Data and methodology}

A daily rainfall dataset, the Climate Hazards Group Infrared Precipitation with Station Data (CHIRPS), is utilized. The CHIRPS dataset spans from 1981 to present day at $0.25^{\circ} \times 0.25^{\circ}$ longitude-latitude horizontal resolution and is based upon satellite infrared and rain gauge measurements over West Africa (Funk et al. 2014, 2015). Daily June-September (JJAS) precipitation measurements are considered to characterize Sahel precipitation indices over the area $\left(20^{\circ} \mathrm{W}-10^{\circ} \mathrm{E}\right.$, $\left.10^{\circ}-20^{\circ} \mathrm{N}\right)$. Note that similar results are obtained for daily July-September (JAS) measurements. Depending on percentile thresholds, indices are stratified in terms of daily rainfall intensity: low ( $<50$ th $)$, moderate $(<75$ th $)$, heavy ( $>75$ th), and extreme ( $>95$ th) events. Therefore, the moderate category also includes low precipitation events. Likewise, the heavy category contains extreme daily events. Thresholds are calculated over each Sahel grid point separately, with rainy days defined as days in which the rainfall amount is greater than $1 \mathrm{~mm}$. Subsequently, for each precipitation category, the gridpoint precipitation values fulfilling the intensity criterion are retained and averaged over the total Sahel area for each JJAS season. Then, the seasonal anomalies of these indices are calculated by removing the seasonal mean. The obtained time series are standardized and high-pass filtered (Lanczos; 8-yr cutoff period) to keep only with interannual variability (one data point per year). The resultant time series are considered as our rainfall indices along the whole study.

The SST dataset from the Met Office Hadley Centre Sea Ice and Sea Surface Temperature dataset (HadISST) is used and regressed on precipitation indices to search for possible oceanic teleconnections. The SST data have a horizontal grid of $1^{\circ} \times 1^{\circ}$ in longitude-latitude (Rayner et al. 2003). The indices of ENSO, TNA, and the Mediterranean Sea Index (MSI) are computed based on highpass-filtered SST anomalies, averaged over the regions $180^{\circ}-80^{\circ} \mathrm{W}, 5^{\circ} \mathrm{S}-5^{\circ} \mathrm{N} ; 60^{\circ}-20^{\circ} \mathrm{W}, 5^{\circ}-30^{\circ} \mathrm{N}$; and $5^{\circ} \mathrm{W}-30^{\circ} \mathrm{E}$, $30^{\circ}-45^{\circ} \mathrm{N}$, respectively.

To analyze the underlying physics of the identified teleconnection mechanisms, atmospheric data from the European Center for Medium-Range Weather Forecasts (ECMWF) ERA-Interim reanalysis (period 1979-2017) are also utilized. ERA-Interim is provided at $0.75^{\circ} \times 0.75^{\circ}$ horizontal resolution with 60 vertical atmospheric levels, from the surface up to $0.1 \mathrm{hPa}$ 
(Dee et al. 2011). The dynamical fields analyzed to compute JJAS seasonal anomalies are (i) specific humidity at $850 \mathrm{hPa}$; (ii) moisture flux at $850 \mathrm{hPa}$; and (iii) vertical instability, which is the difference of wind divergence between the 200- and 850-hPa pressure levels (hereafter DIV200/850; Gómara et al. 2018). Positive DIV200/850 values thus indicate vertical destabilization and upward motion of air (the reverse is true for negative values). The sea level pressure (SLP) is also used (instead of the DIV200/850 parameter) for the MSI, as the influence of the Mediterranean Sea in Sahelian rainfall has been found to take place through anomalous moisture advection at surface levels, mediated by the SLP gradient between the Gulf of Guinea and the Sahara (Rowell 2013; Fontaine et al. 2010; Gómara et al. 2018).

To identify covariability between fields, regression maps are calculated by projecting a time-evolving field onto the time series associated with a particular index. For each grid point $(i, j)$, a linear regression is done between an index $I$, which is standardized (e.g., rainfall or TNA), and the value of anomalous of the variable $Y$ at that grid point:

$$
R(i, j)=\sum_{t=1}^{n} Y(i, j, t) I(t)
$$

To further analyze the atmospheric stability associated with moderate/weak and heavy/extreme precipitation events over the Sahel, moist static energy (MSE) is calculated:

$$
\mathrm{MSE}=\underbrace{C_{P} T}_{\mathrm{SH}}+\underbrace{g z}_{\mathrm{PE}}+\underbrace{L_{v} q}_{\mathrm{LH}}
$$

where $T$ is the temperature, $C_{P}$ is the specific heat at constant pressure, $z$ is the height, $g$ is the gravitational acceleration, $L_{v}$ is the latent heat of vaporization at $0^{\circ} \mathrm{C}$, and $q$ is the specific humidity. MSE thus combines the contributions from latent heat (LH), sensible heat ( $\mathrm{SH})$, and potential energy (PE) terms. The MSE is a useful tool to investigate the relative roles of moisture and temperature changes to this stability (Sheen et al. 2017; Hill et al. 2017). An increasing MSE with altitude denotes a stable atmosphere.

Due to the time limitations posed by the observational datasets, the time interval considered for the study is 1981-2016, a period in which a strong SahelENSO teleconnection has been documented (Janicot et al. 2001; Mohino et al. 2011a; Rodríguez-Fonseca et al. 2011, 2015; Gómara et al. 2018). To analyze the predictability of Sahel daily precipitation events based on SST anomalies, a stepwise multilinear regression

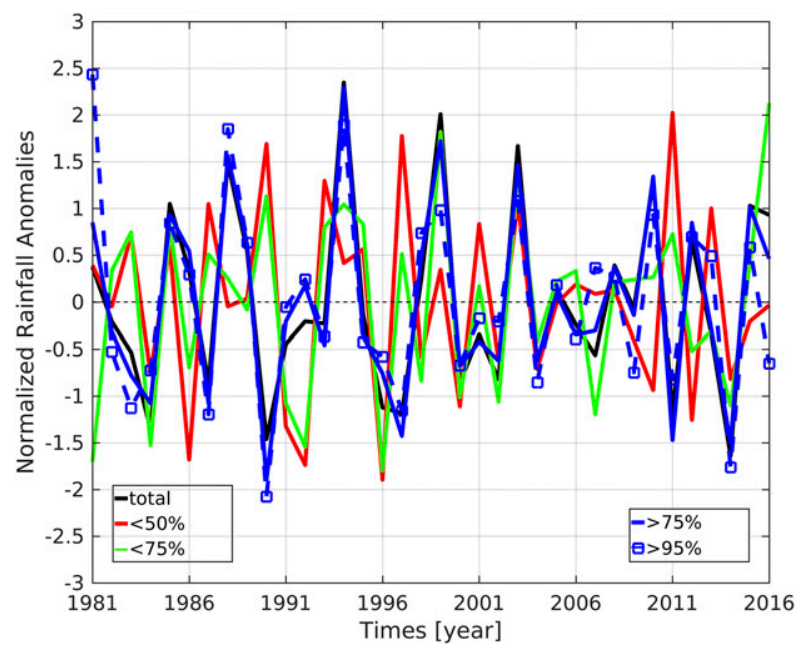

FIG. 1. Normalized Sahel JJAS total (black), low ( $<50$ th percentile; red), moderate $(<75$ th percentile; green), heavy $(>75$ th percentile; blue), and extreme ( $>95$ th percentile; blue dashed line with squares) daily rainfall indices. These indices are built from the CHIRPS datasets and are high-pass filtered. For each precipitation category (associated with a percentile), the gridpoint precipitation values fulfilling the intensity criterion are retained and averaged over the total Sahel area $\left(20^{\circ} \mathrm{W}-10^{\circ} \mathrm{E}, 10^{\circ}-20^{\circ} \mathrm{N}\right)$ for each JJAS season.

statistical model is utilized for the same period (cf. section 3d). Finally, a two-tailed $t$ test that accounts for autocorrelation of the time series (Bretherton et al. 1999 ) is used throughout the paper for testing statistical significance of the results ( $95 \%$ confidence interval).

\section{Results}

\section{a. Interannual variability of Sahel moderate and heavy daily rainfall}

Total Sahelian JJAS rainfall variability is separated into the contributions of low, moderate, heavy, and extreme daily rainfall events. A first result arises when performing this separation, as moderate and heavy daily rainfall variability indices show very different interannual time evolutions, appearing to be caused by distinctive physical mechanisms. Figure 1 shows that, except for some periods and years like 1993-96, 19982002, 2014, and 2015, the time evolution of these indices is decoupled. This is especially evident before 1993 and after 2005.

Correlation values between low, moderate, heavy, and extreme indices are presented in Table 1. Quantitatively, correlation values between moderate and heavy indices are found to be positive $(0.24)$, but not statistically significant, therefore supporting the conclusion that variability of moderate and heavy rainfall events over the Sahel is decoupled. 
TABLE 1. Cross correlations of Sahel daily rainfall (low, moderate, heavy, and extreme) indices. Boldface indicates statistical significance at the $95 \%$ confidence interval using a Student's $t$ test.

\begin{tabular}{lcrc}
\hline \hline Correlation & Moderate & Heavy & Extreme \\
\hline Low & $\mathbf{0 . 6 4}$ & -0.19 & -0.12 \\
Moderate & & 0.24 & -0.04 \\
Heavy & & & $\mathbf{0 . 8 9}$ \\
\hline
\end{tabular}

To quantify the imprint of each of the rainfall intensity categories on the total rainfall index, their correlation values are provided in Table 2, together with their standard deviations. The correlation value between moderate and total precipitation indices is 0.46 and that between heavy and total precipitation is 0.97 . Consequently, interannual variability of total Sahel rainfall is found to be mainly dominated by heavy daily precipitation events. However, regarding the contribution to yearly precipitation amount, both heavy and moderate rainfall are important $(51 \%$ and $49 \%$ of the total annual precipitation, respectively). For the remaining categories, the contribution of low daily rainfall events to the total precipitation is found to be more important in terms of yearly rainfall accumulation $(23 \%)$ than in terms of explained interannual variability (cf. Table 2 , right column).

\section{b. SST teleconnection patterns}

Consistent with previous studies (e.g., Rowell 2001; Janicot et al. 2001; Mohino et al. 2011b; Fontaine et al. 2010; Rodríguez-Fonseca et al. 2011), an increase of JJAS Sahel total rainfall is associated with a La Niña-like pattern in the equatorial Pacific and warmer-than-usual SSTs over the Mediterranean and subtropical North Atlantic (Fig. 2a). By linear construction, the opposite is also true for a decrease in total seasonal rainfall. Figures $2 \mathrm{~b}-\mathrm{d}$ show JJAS SST forcing patterns associated with moderate, heavy, and extreme rainfall events, respectively. In this context, please note that similar SST patterns have been found considering slight variations in the total study period (1981-2011, 1981-2012, or 19812013). The enhanced occurrence of moderate daily Sahelian rainfall events is related to an SST warming of the tropical/subtropical North Atlantic (Fig. 2b), while a La Niña-like signal appears over the equatorial Pacific, associated with heavy and extreme daily rainfall events (Figs. 2c,d). Over the North Atlantic a horseshoe pattern, typically associated with the negative phase of the North Atlantic Oscillation (NAO), is also observed in Fig. 2b. Indeed, under a negative NAO phase, the weakening of the trade winds decreases the latent heat flux and sea level pressure over subtropical latitudes, warming the oceanic waters beneath through the wind-evaporation-SST (WES) feedback process
TABLE 2. Correlation values between the total rainfall index and that of low, moderate, heavy, and extreme rainfall are provided in the first column. Standard deviation coefficients of each index are provided in column 2 and the contributions to yearly precipitation amount of each of these categories are in column 3 (calculated by dividing the total rainfall accumulation associated with each category by that associated with the total one). Boldface indicates statistical significance at the $95 \%$ confidence interval using a Student's $t$ test.

\begin{tabular}{lccc}
\hline \hline & $\begin{array}{c}\text { Correlation with } \\
\text { the total index }\end{array}$ & $\begin{array}{c}\text { Std dev } \\
(\mathrm{mm})\end{array}$ & $\begin{array}{c}\text { \% of contribution } \\
\text { to yearly amounts }\end{array}$ \\
\hline Total & $\mathbf{1 . 0 0}$ & 0.28 & 100 \\
Low $(<50$ th $)$ & -0.02 & 0.03 & 23 \\
Moderate $(<75$ th $)$ & $\mathbf{0 . 4 6}$ & 0.06 & 49 \\
Heavy $(>75$ th $)$ & $\mathbf{0 . 9 7}$ & 0.25 & 51 \\
Extreme $(>95$ th $)$ & $\mathbf{0 . 8 0}$ & 0.14 & 16 \\
\hline
\end{tabular}

(Okumura et al. 2001; Czaja and Frankignoul 1999). The Mediterranean (MSI) also shows a significant link with both moderate and heavy/extreme events (correlation values of $0.67,0.62$, and 0.31 for moderate, heavy, and extreme events, respectively; cf. Table 3). The patterns associated with heavy (Fig. 2c) and extreme daily precipitation events (Fig. 2d) mostly resemble those associated with total rainfall (Fig. 2a). Nevertheless, the intensity/extent of the SST anomalies over the Pacific appears enhanced for the case of heavy/extreme daily precipitation events, pointing out to a tropical Pacific forcing as a main driver of intense rainfall, compared to the secondary role of extratropical patterns (North Atlantic and Mediterranean; Figs. 2c,d).

\section{c. Mechanisms of SST teleconnections on Sahel moderate and heavy daily rainfall}

In Fig. 3 the underlying physical mechanisms of the teleconnections identified in Fig. 2 are analyzed. Figure 3a shows that Sahel total rainfall variability is associated with anomalous southwesterly low-level moisture flux, which transports humidity from the north tropical and equatorial Atlantic toward the Sahel (arrows). The moisture advection enhances the available low-level humidity over this area (shadings). Positive vertical instability (DIV200/850) anomalies are also observed over the same region for total rainfall, reflecting low-level wind convergence and upper-level divergence associated with vertical air movement and, potentially, convection (contours).

A similar picture is observed for heavy and extreme daily precipitation events (Figs. 3c,d). Organized deep convective systems are characterized by a baroclinic structure with opposite divergent circulation patterns at upper levels, a feature denoted in contours. The maximum anomalies of low-level humidity are located over 
a) Total

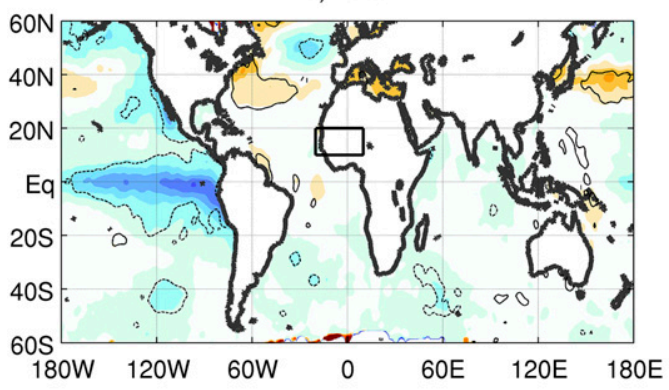

c) Heavy $\left[>75^{\text {th }} \mathrm{p}\right]$

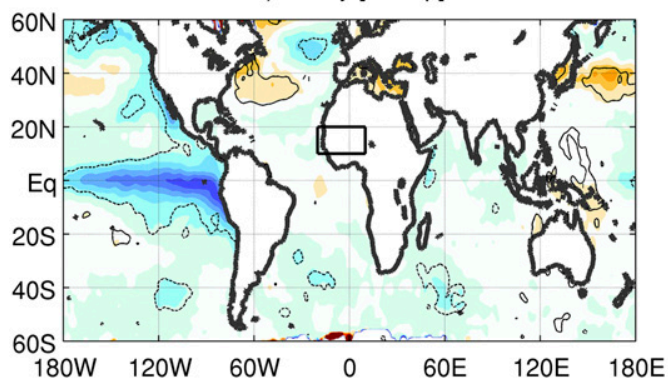

b) Moderate $\left[<75^{\text {th }} \mathrm{p}\right]$

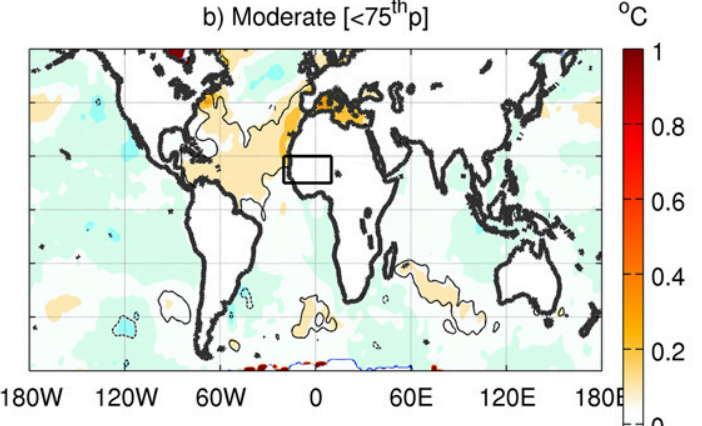

d) Extreme $\left[>95^{\text {th }} \mathrm{p}\right]$

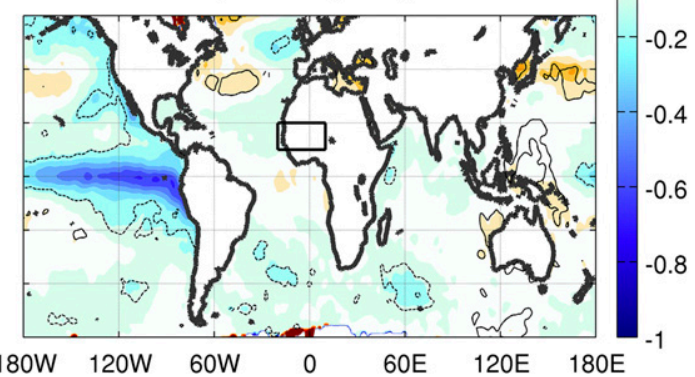

FIG. 2. Regression map of JJAS (1981-2016) SST anomalies $\left({ }^{\circ} \mathrm{C}\right.$ per standard deviation of the rainfall index) onto (a) total, (b) moderate, (c) heavy, and (d) extreme normalized precipitation indices. Contours delimit the $95 \%$ confidence interval using a Student's $t$ test. The black box over West Africa delimits the Sahel region considered in this paper.

the central and eastern Sahel (Figs. 3c,d). This flow is driven by the large-scale circulation and probably associated with La Niña, which acts to promote vertical air destabilization over the Sahel (Joly and Voldoire 2009).

Conversely, for moderate daily rainfall events (Fig. 3b), local negative DIV200/850 anomalies are present over the Sahel region, suggesting that local convection is not enhanced for these events. There is, however, enhanced low-level humidity stemming from the TNA region, which is consistent with a warming in the tropical/subtropical North Atlantic waters (Fig. 2b). Such warming acts to increase evaporation over these areas and therefore moisture advection toward the Sahel.

These results indicate that heavy and extreme daily rainfall events seem to be mainly associated with ENSO, while moderate events seem to be linked to SST anomalies from the TNA. SST variability over the Mediterranean appears to be important for both moderate and heavy/extreme rainfall (cf. Figs. 2b-d). However, regarding the mechanism, Figs. $3 \mathrm{~b}$ and $3 \mathrm{c}$ show no clear significant low-level humidity flux from the Mediterranean toward the Sahel.

To test the robustness of the main dynamical mechanisms proposed, a reverse methodological approach is carried out in Fig. 4. First, worldwide SST anomalies are regressed onto ENSO, TNA, and MSI indices (Figs. 4a-c). Second, atmospheric variables from Fig. 3 are also regressed on TNA and ENSO indices (Figs. 4d,e). The same analysis is done for the MSI index by just replacing the DIV200/850 parameter by SLP, as explained before (Fig. 4f).

For a TNA positive phase (as for moderate rainfall events), the regression map shows enhanced low-level specific humidity over the Sahel region, transported from the tropical/subtropical North Atlantic (Fig. 4d). In this area, a horseshoe pattern (Fig. 4a), together with a negative phase of the NAO, may act to reduce the trade

TABLE 3. Stepwise regression of the three main predictors (MSI, TNA, and Niño-3) onto Sahel August moderate, heavy, and extreme rainfall indices at lag 0 . Stepwise regression is the iterative application of forward selection and background elimination; it allows us to select the best predictor for each Sahel rainfall index. Best predictors are associated with the status "in," and those that do not increase the model skill are associated with the status "out." The correlation values between SST indices and that of Sahel rainfall are also added in parentheses (significant threshold of 0.28 according to the Student's $t$ test at 95\%).

\begin{tabular}{lccc}
\hline \hline & MSI & TNA & Niño-3 \\
\hline Moderate $(<75$ th $)$ & In $(0.67)$ & In $(0.67)$ & Out $(0.04)$ \\
Heavy $(>75$ th $)$ & In $(0.62)$ & Out $(0.44)$ & In $(-0.30)$ \\
Extreme $(>95$ th $)$ & In $(0.31)$ & Out $(0.15)$ & In $(-0.35)$ \\
\hline
\end{tabular}



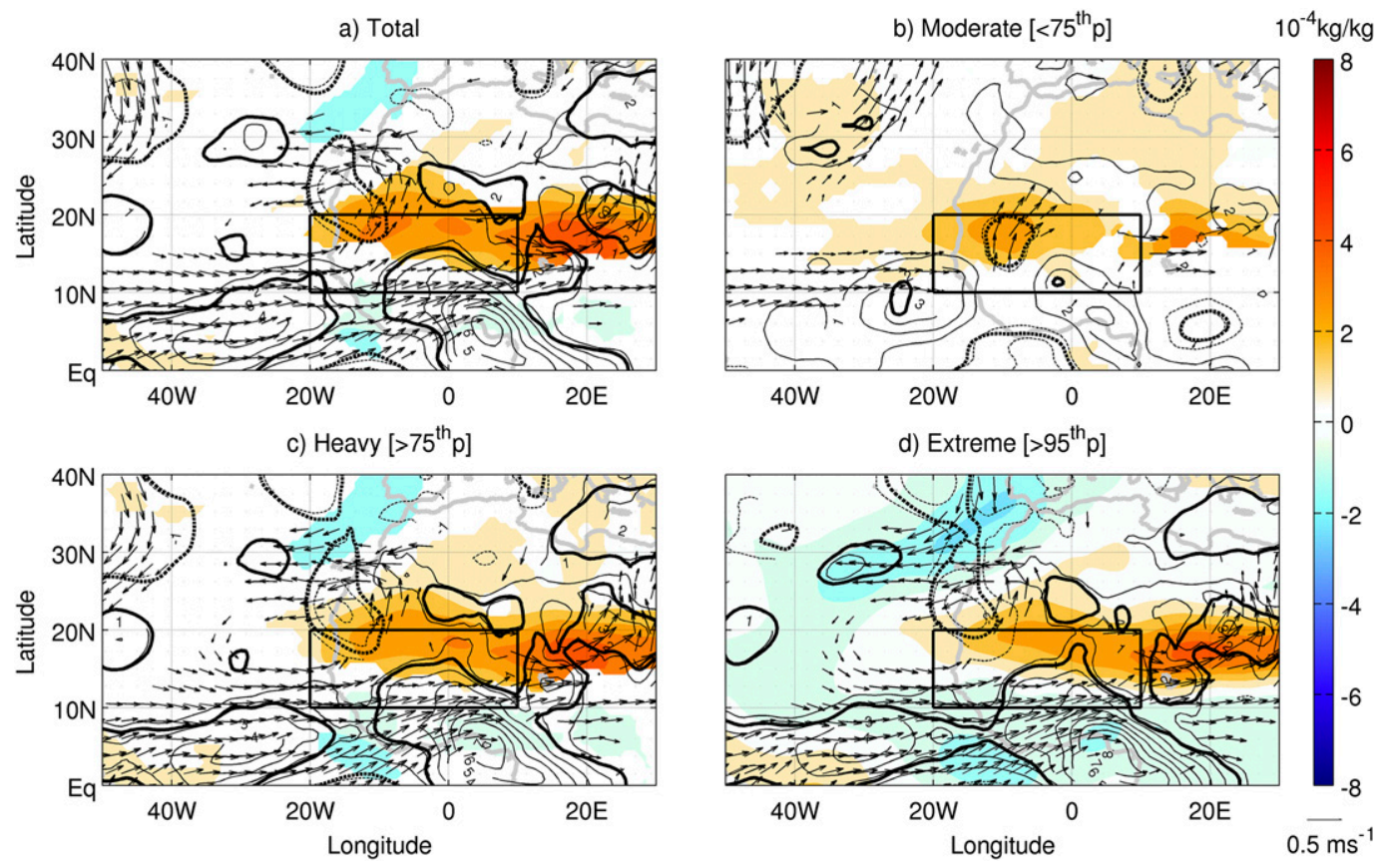

FIG. 3. Regression of JJAS (1981-2016) anomalies of specific humidity at $850 \mathrm{hPa}$ (colors; $\mathrm{kg} \mathrm{kg}^{-1}$ ), DIV200/850 (contours; $10^{-7} \mathrm{~s}^{-1}$ ), and moisture flux at $850 \mathrm{hPa}$ (arrows; $\mathrm{kg} \mathrm{kg}^{-1} \mathrm{~m} \mathrm{~s}^{-1}$ ) onto (a) total, (b) moderate, (c) heavy, and (d) extreme normalized precipitation indices. Heavy contours delimit the $95 \%$ confidence interval using a Student's $t$ test. The black box over West Africa delimits the Sahel region considered in this paper.

winds, thus increasing humidity advection over the Sahel (from a warming of the TNA).

For an ENSO negative phase (as for Sahel heavy/ extreme events), results show enhanced northeastward low-level moisture flux, transporting humidity from the northern tropical and equatorial Atlantic toward the Sahel. Such anomalous flow is again consistent with the vertical destabilization (stabilization) that La Niña (El Niño) induces over the Sahel, promoting wind convergence (divergence) at $850 \mathrm{hPa}$ and divergence (convergence) at $200 \mathrm{hPa}$ (contours in Fig. 4e). Figure $4 \mathrm{~b}$ also reveals that an equatorial Pacific cooling (warming) is associated with a concomitant equatorial Atlantic warming (cooling). The simultaneous appearance of these anomalies for the period considered (1981-2016) has been reported in previous studies (Rodríguez-Fonseca et al. 2009).

Finally, for MSI, Fig. 4f shows that a warmer Mediterranean enhances evaporation and strengthens the Sahara heat low, thus increasing the pressure gradient between the Sahara and Gulf of Guinea in agreement with previous studies (Rowell 2013; Peyrillé et al. 2007; Fontaine et al. 2010; Gaetani et al. 2010; Gómara et al. 2018). The increased meridional pressure gradient promotes a further penetration of the monsoonal flow from the Gulf of Guinea (anomalous southwesterly positive moisture flux). Figure $4 \mathrm{f}$ also shows that this meridional circulation strengthens with changes in the heat low, combined with a large change of westerly flow from the tropical North Atlantic, which also increases moisture and heat transport into the Sahel (Martin and Thorncroft 2014). In addition, as it will be shown later, the inclusion of the MSI leads to enhanced predictive skill (cf. section 3d).

To further analyze the origin of rainfall variability and its relation to intensity, an analysis of MSE [Eq. (2)] is subsequently performed in Fig. 5. For the variability of moderate and extreme daily precipitation events, the contribution of the PE component (Fig. 5d) is negligible compared to the LH and SH terms (Figs. 5b,c). Attending to moderate and extreme daily precipitation vertical profiles, the stronger differences arise in the low tropospheric levels (Figs. 5a,b).

MSE associated with low to moderate daily precipitation decreases strongly with altitude compared to that associated with extremes (Fig. 5a), which suggests instability in the low levels (Sheen et al. 2017). Figure 5c shows that this strong decrease is mainly explained by the LH component. However, the LH component decreases with a similar rate for extremes too. Surface evaporation is important over land where soil moisture is available, a feature that is very important in moderate rainfall events, where MSE is controlled by LH. In contrast, during extreme daily precipitation events, the 
a) SST regmap onto TNA

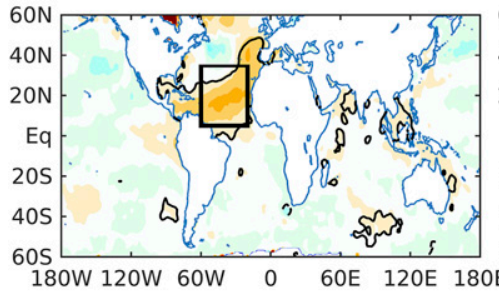

b) SST regmap onto (-1x) ENSO

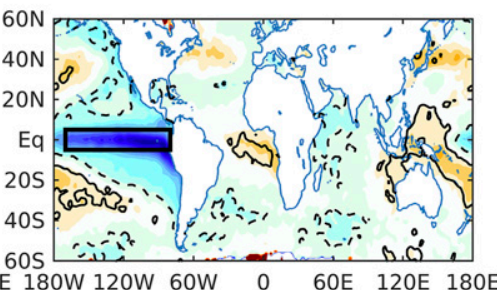

c) MSL regmap onto MSI

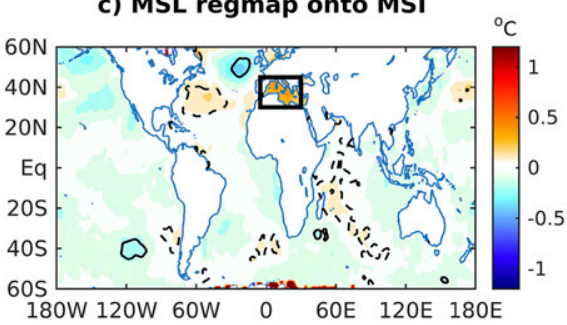

f) Atm regmap onto MSI

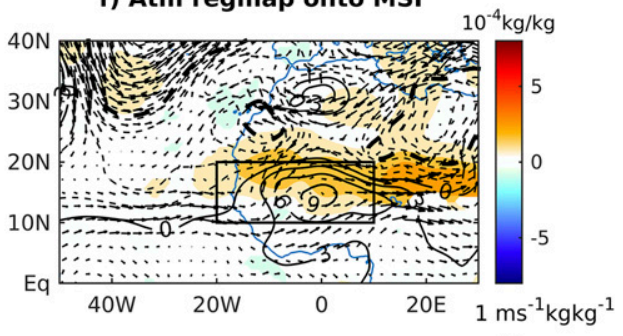

d) Atm patterns regmap onto TNA

e) Atm regmap onto (-1x) ENSO
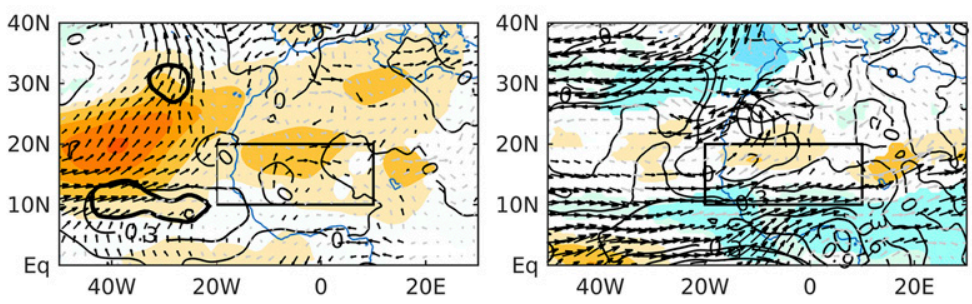

FIG. 4. Global JJAS SST anomalies regressed onto the (a) TNA, (b) ENSO, and (c) MSI indices $\left({ }^{\circ} \mathrm{C}\right.$ per standard deviation index). Anomalies of specific humidity at $850 \mathrm{hPa}$ (colors; $\mathrm{kg} \mathrm{kg}^{-1}$ ), DIV200/850 (contours; $0.3 \times 10^{-6} \mathrm{~s}^{-1}$ interval), and moisture flux at $850 \mathrm{hPa}$ (black and gray arrows for significant and nonsignificant anomalies, respectively; $\mathrm{kg} \mathrm{kg}^{-1} \mathrm{~m} \mathrm{~s}^{-1}$ ) regressed onto (d) TNA and (e) ENSO indices. (f) Anomalies of specific humidity at $850 \mathrm{hPa}$ (colors; $\mathrm{kg} \mathrm{kg}^{-1}$ ), SLP (contours; $3 \mathrm{~Pa}$ interval), and moisture flux at $850 \mathrm{hPa}$ (black and gray arrows for significant and nonsignificant anomalies, respectively; $\mathrm{kg} \mathrm{kg}^{-1} \mathrm{~m} \mathrm{~s}^{-1}$ ) regressed onto the MSI index. Note that for (b) and (e), the ENSO index is here multiplied by -1 in order to catch the La Niña effect. Contours in (a) and (b) delimit the $95 \%$ confidence interval using a Student's $t$ test, while in (c) and (d) only significant anomalies have been plotted. The continental box in (d)-(f) delimits the Sahel region while boxes in (a)-(c) correspond to the TNA, ENSO, and MSI indices areas, respectively.

contribution of the LH component (Fig. 5c) is balanced at low tropospheric levels by strong negative values of $\mathrm{SH}$ (Fig. 5b). These strong negative SH values could depict the equilibrium response once convection has overturned the vertically integrated temperature column (Wei et al. 2014). At medium and upper levels $(500-200 \mathrm{hPa})$, the MSE profile is more unstable for extreme than for moderate precipitation events (Fig. 5a). This can be related to both $\mathrm{LH}$ and $\mathrm{SH}$ components. On the one hand, the upper troposphere (400-200 hPa) is colder in the extreme case, consistent with a tropical cooling due to La Niña (Lintner and Chiang 2007), which affects the SH component. On the other hand, the middle troposphere is more humid in the extreme case, which would be related to a stronger vertical rise of moisture-rich air (Fig. 3d).

In summary, moderate events seem to be controlled by instability in lower levels associated with changes in latent heat fluxes due to surface evaporation. The influence of the subtropical North Atlantic and Mediterranean SSTs is felt through surface processes and moisture flux advection from the warm seas. In contrast, extreme rainfall events are controlled by upper-level instability and convective precipitation systems, a mechanism consistent with ENSO remote influence, as the teleconnection with ENSO is related to changes in the upper-level divergence, favoring (La Niña) or inhibiting (El Niño) the instability in the upper levels.

This hypothesis is confirmed in Fig. 6, where air temperature anomalies from the surface up to $200 \mathrm{hPa}$ are regressed on moderate and extreme precipitation indices and averaged over the corridor $0^{\circ}-17^{\circ} \mathrm{N}$. Similar results (but with a weaker signal) are obtained when limiting the latitudinal band to that of Sahel $\left(10^{\circ}-20^{\circ} \mathrm{N}\right)$. The extended band has therefore been chosen in order capture a better ENSO signature, as the teleconnection associated with the latter is stronger near the equator.

During moderate daily rainfall events, as shown by the SH anomalies profile (Fig. 5b), atmospheric temperature anomalies are significantly warmer over the tropical North Atlantic (Fig. 6a). These results are consistent with the presence of warmer waters over the near subtropical North Atlantic, which heat up the air immediately above. During extreme daily rainfall events, in addition to weak upper-level cooling over the Sahel, associated with La Niña influence (the opposite takes place for El Niño), the temperature anomalies exhibit a strong and significant low-level cooling in the lower levels (Fig. 6b). This cooling could be associated with the temperature equilibrium response, once convection has overturned the column (Fig. 5b). Consequently, MSE is quasi constant with altitude for extreme daily 

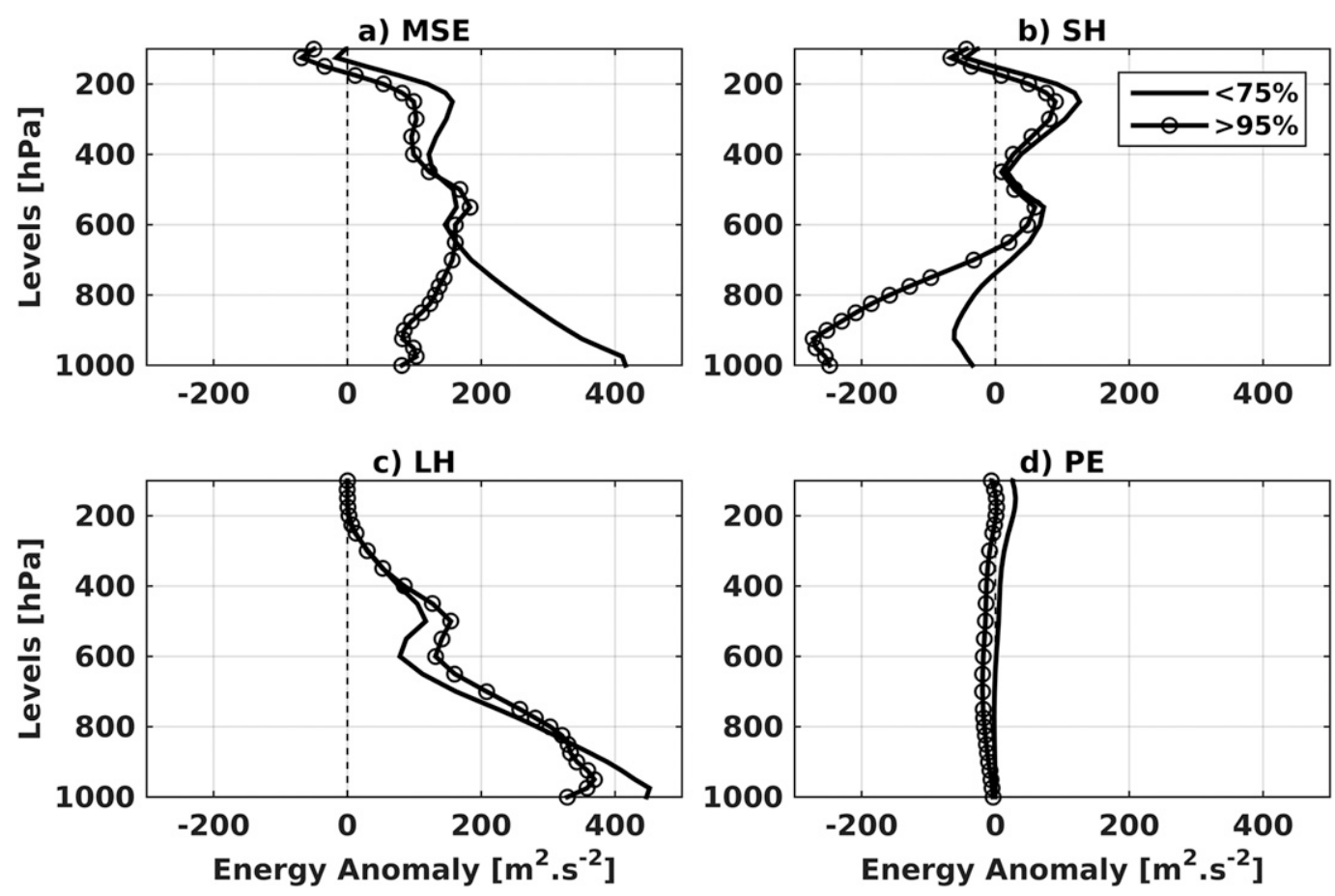

FIG. 5. Regression of JJAS (1981-2016) anomalies of (a) MSE and its components, (b) SH, (c) LH, and (d) PE onto moderate (line) and extreme (circles) normalized rainfall indices. The regressions onto the Sahel indices are done in each grid point of the Sahel box, and the vertical profiles correspond to anomalies averaged over the Sahel box.

precipitation at lower levels, due to the balance of $\mathrm{SH}$ and LH terms. In this context, it is well known that the evaporation (sublimation) of rain (ice) falling droplets produces a strong cooling in convective systems, which subsequently strengthens the downward current itself and cold pools. The latter are considered as fundamental ingredients for deep convection (Torri et al. 2015). However, due to their mesoscale characteristics, their direct causality on seasonal and spatial averaged rainfall indices from this study is extremely hard to detect (Wei et al. 2014).

The results from this section are entirely consistent with the same analysis applied to nonfiltered data (linear trends removed), as the SST patterns considered are mainly interannual (ENSO, TNA, Mediterranean).

\section{d. Predictability of Sahel moderate and heavy/extreme daily rainfall at interannual time scales}

As described in the previous section, the key SST indices associated with JJAS Sahel rainfall variability at interannual time scales are the TNA, ENSO, and MSI.

To assess the potential predictability of rainfall events over the Sahel, different predictors are selected based on these SST indices. Potential predictors for each Sahel rainfall index are identified by applying a stepwise multilinear regression. This method permits us to automatically identify the relevant SST predictors for each rainfall index and disregard those which do not increase model skill (forward selection and backward elimination; von Storch and Zwiers 1999). Subsequently, the selected predictors for each index are utilized to perform a leave-one-out cross-validated hindcast at lag 0 (predictors/predictands based on the same monthly period of August). In this way, the linear regression model is built for each year to be predicted, calculating the coefficients of the model with all the years in our database except the one that is predicted (ter Braak and Juggins 1993; Birks 1981). The hindcast is performed and correlated with the omitted observations. The same analysis is extended by utilizing the same SST predictors from the previous months to assess predictability of Sahel moderate and heavy daily rainfall events. Unlike in the previous analyses, all considered indices and anomalies in this section are calculated on a monthly basis. As a result, all selected rainfall predictands (precipitation indices) are computed for the month of August. SST predictors considered for lag 0 are thus simultaneous SST anomalies. Lag- 1 forecasts take into account SST anomalies from the previous month of the same year (July), and so on back to one year in advance.

In Table 3, the main SST predictors utilized to predict rainfall indices at lag 0 are provided. As expected, the 


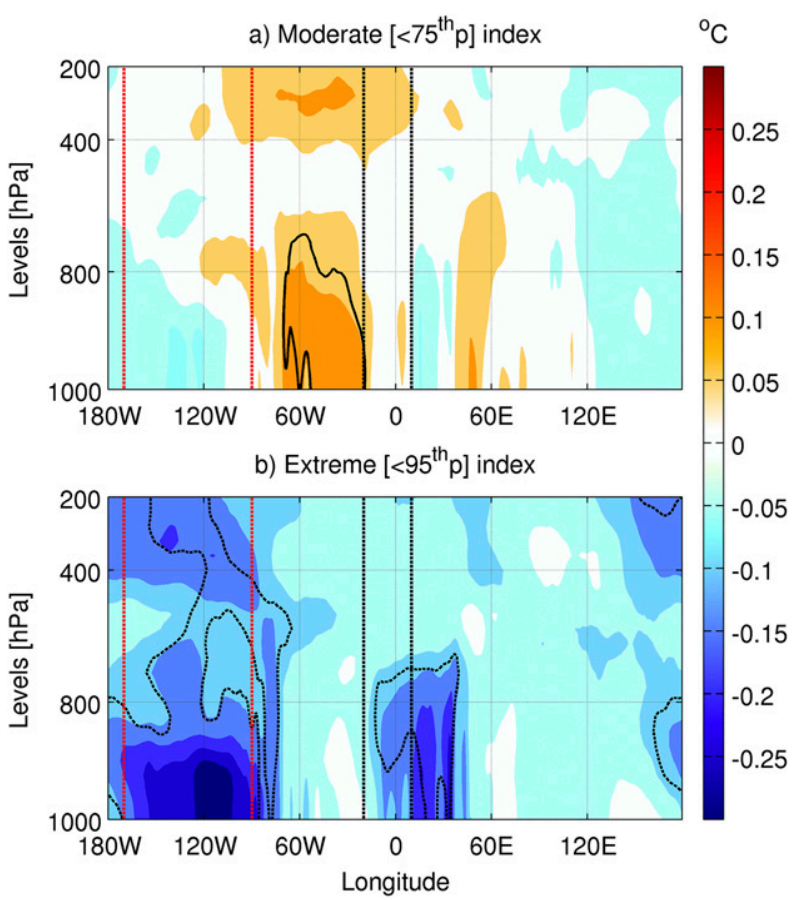

FIG. 6. Regression of JJAS (1981-2016) vertical (1000-200 hPa) temperature anomalies onto (a) moderate and (b) extreme normalized rainfall indices. Temperature anomalies are averaged over the latitudinal corridor $0^{\circ}-17^{\circ} \mathrm{N}$ for each pressure level (colors; ${ }^{\circ} \mathrm{C}$ ) Black dotted contours delimit significant anomalies at the $95 \%$ confidence interval. Vertical black dotted bars delimit longitudinal boundaries of the Sahel region.

regression model considers the TNA as a main predictor of moderate Sahel rainfall, together with the MSI. For heavy/extreme precipitation, both ENSO and MSI are considered as skillful predictors. This outcome is fully consistent with the findings of Figs. 2-6.

Based on these predictors, the cross-validation hindcast for each rainfall index at lag 0 is provided (Fig. 7). The model is able to reproduce the temporal evolution of Sahel rainfall indices with high significant skill $(0.73,0.69$, and 0.50 correlation coefficients for moderate, heavy, and extreme rainfall indices, respectively; $95 \%$ confidence interval).

In Fig. 8 the same analysis is extended to consider SST predictors from lag 0 (August) to -12 (August of year -1 ). In the figure, lagged correlations between rainfall predictands and SST predictors are provided with bars, whereas skill scores from the multiregression model are provided with markers. For moderate rainfall events, significant forecast skill is obtained from MSI and TNA predictors 2 months ahead (Fig. 8a; 95\% confidence level). In other words, the model is able to predict August moderate rainfall based on MSI and TNA SST predictors from June. This outcome is also consistent with lagged correlation values, which are statistically significant (same confidence interval) for both MSI (thin bars) and TNA (wide bars) back to lag -2 .

For heavy and extreme rainfall indices the forecast window (based on MSI and ENSO SST predictors) is even increased to 3 and 4 months in advance (May/ April), respectively (Figs. 8b,c). Also, the lagged correlations with the MSI index decrease more rapidly backward in time than for ENSO. Correlation values between ENSO and the rainfall indices remain significant from April on (lag -4), whereas those of MSI just reach the previous July (lag -1$)$. The fact that the Mediterranean variability is stronger during the summer months may be behind this behavior (Gaetani et al. 2010). Finally, no correlation is found between August heavy/extreme precipitation anomalies and ENSO during the previous winter (December/January), suggesting that the observed teleconnection takes place during the onset phase of La Niña/El Niño.

\section{Conclusions and discussion}

The contributions, variability, and teleconnections of different types of precipitation, stratified in terms of intensity, have been analyzed over the Sahel. For this purpose, a precipitation dataset (CHIRPS), a sea surface temperature database (HadISST), and a reanalysis product (ERA-Interim) have been analyzed during the summer boreal season (June-September) over 36 consecutive years (1981-2016). Rainfall categories have been built upon gridpoint percentile thresholds during rainy days (days with precipitation amount greater than $1 \mathrm{~mm})$ as follows: low $(<50$ th $)$, moderate $(<75$ th $)$, heavy $(>75$ th), and extreme ( $>95$ th) daily rainfall events. For each category, precipitation values have been retained and averaged over the area $\left(20^{\circ} \mathrm{W}-10^{\circ} \mathrm{E}, 10^{\circ}-20^{\circ} \mathrm{N}\right)$. Last, seasonal precipitation anomalies have been calculated, and a high-pass filter has been applied to the time series to keep only the interannual variability (allowed oscillation periods from 1 to 8 years).

Evidence has been presented that total Sahelian rainfall variability is dominated by the occurrence/ absence of heavy and extreme daily rainfall events, rather than moderate or low rainfall episodes, whose variability and teleconnections are markedly different (Tables 1, 2; Fig. 1).

On the one hand, Sahel heavy and extreme precipitation variability is mainly linked to ENSO and, to a lower extent, Mediterranean SST anomalies (MSI). During La Niña episodes (Figs. 2c,d), the induced anomalous circulation over the Sahel enhances vertical destabilization, promoting air convergence at 

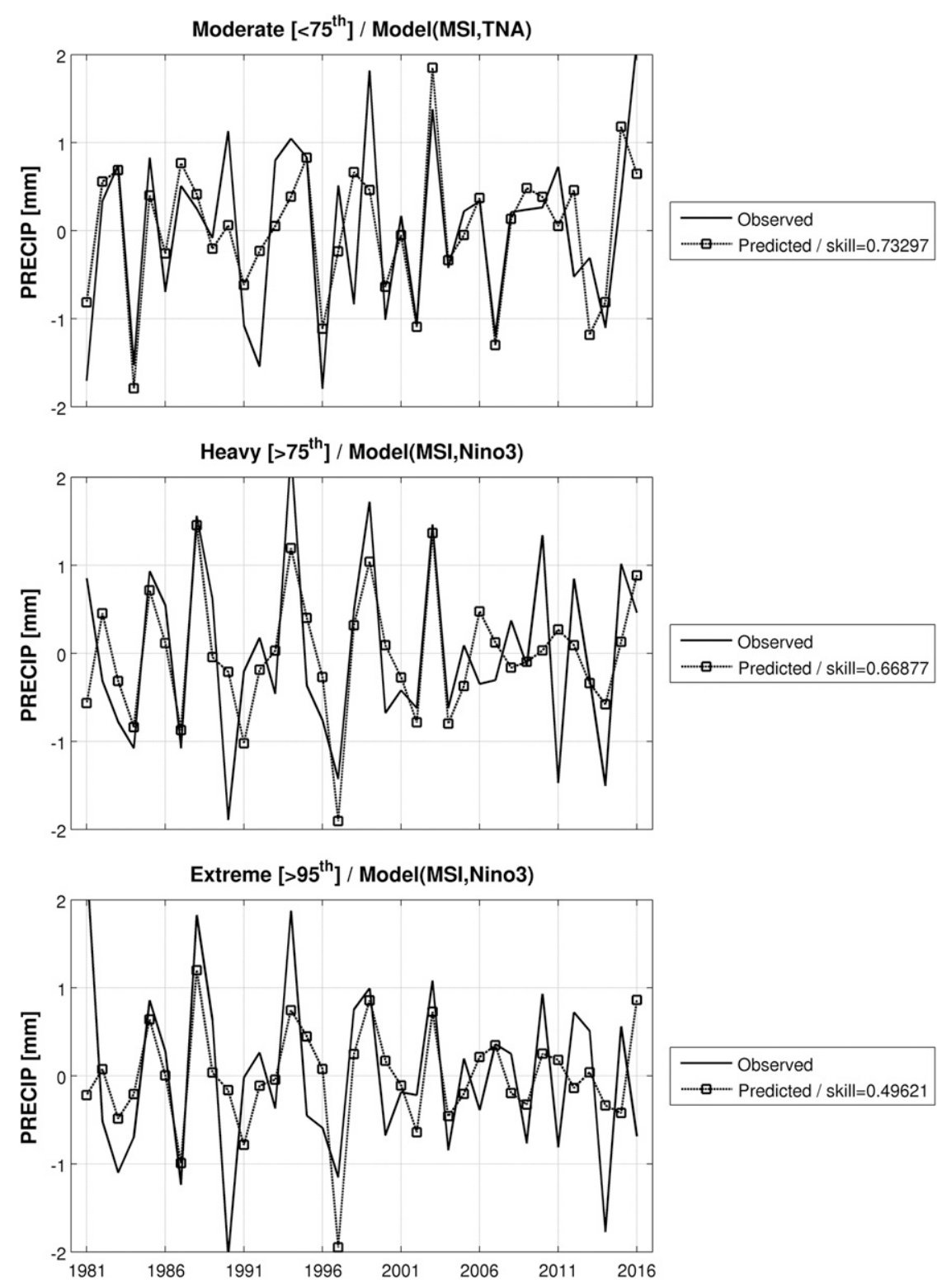

FIG. 7. Cross-validated hindcast of Sahel August (top) moderate, (middle) heavy, and (bottom) extreme rainfall indices based on predictors selected from the stepwise regression (Table 4). Note that the significant threshold for the model skill is equal to 0.2752 .

lower levels and divergence at upper levels (Figs. 3c,d and 5). Such conditions, together with the penetration of moisture-rich air from the Gulf of Guinea toward the Sahel (Figs. 3c,d), create a very favorable environment for convection and thus heavy and extreme rainfall occurrence (Figs. 5, 6b). The reverse holds during El Niño and negative MSI episodes.

On the other hand, moderate rainfall variability is primarily associated with TNA and also Mediterranean SST anomalies (Fig. 2b). When these regions' SSTs are warmer than average, enhanced moisture transport from the equatorial and north tropical Atlantic toward the Sahel is triggered (Sheen et al. 2017), producing an increase of humidity availability over the region (Fig. 3b). In this case, the vertical atmospheric stability is reduced over the Sahel (Fig. 3b) and environmental conditions may be favorable for the formation of horizontal stratiform clouds (Figs. 5, 6a), potentially responsible for the moderate precipitation events. As before, these conditions are reversed for negative TNA and Mediterranean SST anomalies. 

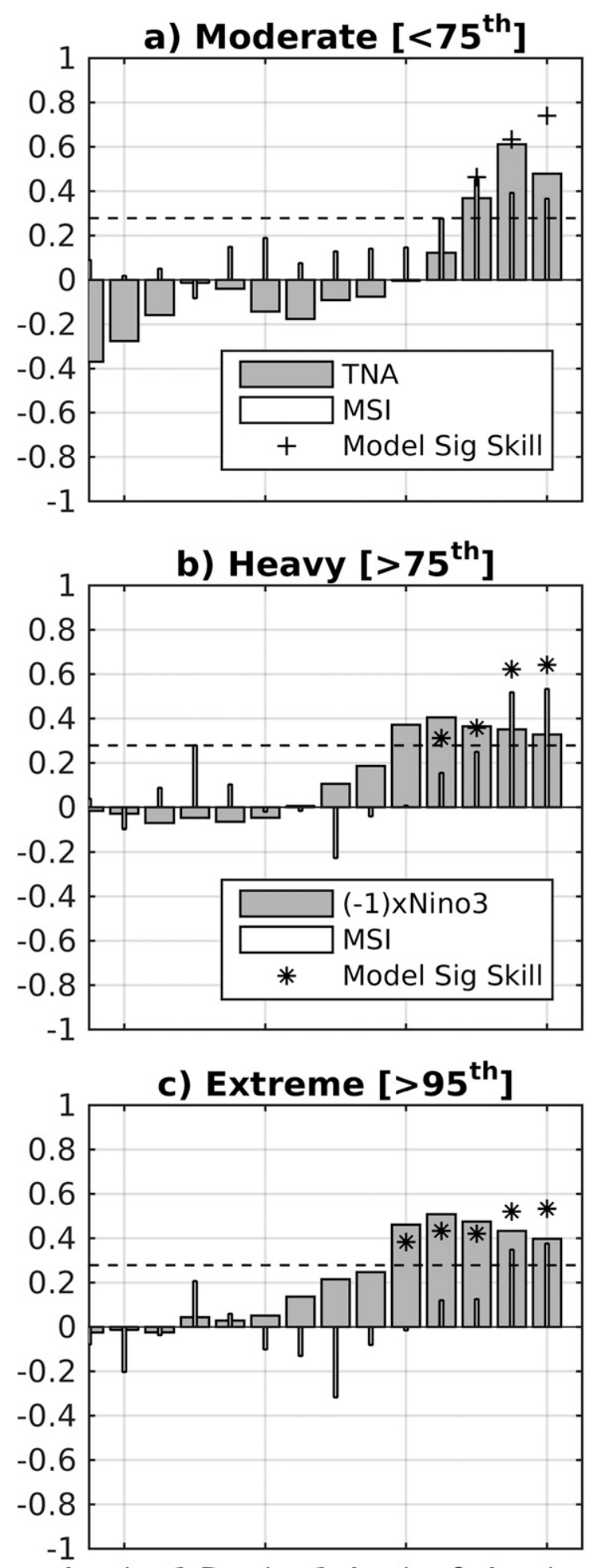

Aug/yr-1 Dec/yr-1 Apr/yr 0 Aug/yr 0

FIG. 8. Lagged correlation and cross-validation hindcast of Sahel (a) moderate, (b) heavy, and (c) extreme rainfall indices for August. Bars denote lagged correlations on a monthly basis between August precipitation indices (predictands) and preceding SST anomaly indices (predictors) from Table 4. The dashed
The Atlantic influence is associated with enhanced available humidity in the lower and medium levels of the troposphere. The main difference with the Pacific forcing is not the moisture advection, but the vertical destabilization of the atmosphere. For the latter, air uplift is promoted and, therefore, so are heavy precipitation events from deep convection, including organized mesoscale or synoptic systems such as mesoscale convective systems or African easterly waves (AEWs). According to Okonkwo (2014), a La Niña event over the Pacific increases the frequency of AEWs. One can therefore expect a stronger link between extreme rainfall events and AEWs. These AEWs are a major source of synoptic-scale rainfall variability throughout West Africa (Skinner and Diffenbaugh 2013; Martin and Thorncroft 2015). Following the approach from Diedhiou et al. (1998) for the identification of AEWs, in our case the number of AEWs associated with heavy rainfall $(22 \%)$ is 2 times higher than that associated with moderate ones (11\%; cf. Table 4).

In terms of yearly precipitation amounts, moderate and heavy daily rainfall contributions are of the same order of magnitude ( $\sim 50 \%$; Table 2$)$. This is an important result when tackling, for instance, climate services and impacts in agriculture, as heavy daily precipitation events have more impact than extreme ones and contribute more on interannual variability (cf. Table 2, first column). Some signals over the Mediterranean have been found in relation to heavy daily rainfall events (Fig. 2c), thus suggesting that these results might complement those relating recent trends in Mediterranean warming on Sahelian recovery (Park et al. 2016; Biasutti 2016).

Finally, a stepwise multilinear regression model has been applied to identify the most relevant SST predictors of each rainfall index at different forecast windows. For this purpose, indices of moderate, heavy, and extreme daily precipitation have been computed based on August monthly anomalies (predictands). Monthly SST anomaly indices (ENSO, TNA, and MSI) from the same month (lag 0), and the previous ones (back to lag -12), have been considered as predictors. Results indicate that moderate, heavy, and extreme Sahel rainfall anomalies can be predicted with high confidence utilizing SST predictors several months in advance.

horizontal line delimits the statistical significance (95\% confidence level) for correlation. Markers are plotted whenever the regression model skill is statistically significant: crosses (predictors TNA and MSI considered), stars [predictors Niño-3 $\times(-1)$ and MSI considered]. Note that the legend in (b) is for (b) and (c). 
TABLE 4. AEWs identification. An AEW is detected when the 2-9-day prefiltered meridional winds at $700 \mathrm{hPa}$ are greater than the value of its standard deviation at $17.5^{\circ} \mathrm{N}, 0^{\circ} \mathrm{W}$. Intersection at lag 0 with moderate, heavy, and extreme daily rainfall occurrence and the passage of AEWs have been applied to estimate values within the table.

\begin{tabular}{lccc}
\hline \hline \multicolumn{1}{c}{ Period 1981-2016 } & Moderate & Heavy & Extreme \\
\hline Total number of daily events & 11817 & 1240 & 248 \\
$\begin{array}{l}\text { Total number of daily events } \\
\text { coinciding with AEWs }\end{array}$ & 1403 & 278 & 40 \\
Percent (\%) & 11.87 & 22.42 & 16.13 \\
\hline
\end{tabular}

TNA and MSI predictors from 2 months in advance, together, are able to provide model skill for the prediction of moderate August Sahelian rainfall. Furthermore, Sahel heavy and extreme precipitation anomalies can be predicted up to 3 and 4 months ahead, respectively, considering ENSO and MSI as predictors. The findings provided in this article may have implications on seasonal forecasting of Sahel moderate, heavy, and extreme rainfall daily events. And in this sense, it must be noted that, due to the relative short time period considered (36 years), SST-rainfall links obtained from this study are assumed to remain stable in time. To analyze the impact of nonstationarity in these relationships (Janicot et al. 2001; Mohino et al. 2011a; RodríguezFonseca et al. 2011, 2015; Suárez-Moreno et al. 2018), a longer-period rainfall dataset should be required. An analogous analysis based on regional model data (e.g., CORDEX-Africa), which considers potential nonlinearities in the SST-precipitation relationships, could also be another interesting path for future research.

Acknowledgments. The research leading to these results has received funding from the CSIC ICOOP project, ICOOPB20204, the UCM Cooperation Project 7 from XIV Call; the NERC/DFID Future Climate for Africa programme under the AMMA-2050 project, Grant NE/M020428/1; the Spanish Project CGL201786415-R; and the EU/FP7 PREFACE project under Grant Agreement 603521. Iñigo Gómara was supported by the Spanish Ministry of Economy and Competitiveness (Juan de la Cierva-Formación contract FJCI-2015-23874) and Universidad Politécnica de Madrid (Programa Propio - Retención de Talento Doctor). The Climate Hazards Group InfraRed Precipitation with Station data (CHIRPS) are available from the Climate Hazards Group (http://chg.geog.ucsb. edu/data/chirps/). The Hadley Centre Sea Ice and Sea Surface Temperature dataset (HadISST) is available from the Met Office (https://www.metoffice.gov.uk/ hadobs/hadisst/). The European Center for MediumRange Weather Forecasts (ECMWF) ERA-Interim reanalysis (period 1979-2017) is available from the ECMWF MARS server (https://www.ecmwf.int/en/ research/climate-reanalysis/era-interim). We would also like to acknowledge Julián Villamayor and Chris Taylor for constructive remarks. Finally, we thank the three anonymous reviewers for their helpful comments and suggestions, which have contributed to improve this manuscript.

\section{REFERENCES}

Anyamba, A., J. L. Small, S. C. Britch, C. J. Tucker, E. W. Pak, C. A. Reynolds, J. Crutchfield, and K. J. Linthicum, 2014: Recent weather extremes and impacts on agricultural production and vector-borne disease outbreak patterns. PLOS ONE, 9, e92538, https://doi.org/10.1371/journal.pone.0092538.

Bader, J., and M. Latif, 2011: The 1983 drought in the West Sahel: A case study. Climate Dyn., 36, 463-472, https://doi.org/10.1007/ s00382-009-0700-y.

Biasutti, M., 2016: Hydrology: What brings rain to the Sahel? Nat. Climate Change, 6, 897-898, https://doi.org/10.1038/ nclimate 3080

Birks, H. J. B., 1981: The use of pollen analysis in the reconstruction of past climates: A review. Climate and History: Studies in Past Climates and Their Impact on Man, T. M. L. Wigley, M. J. Ingram, and G. Farmer, Eds., Cambridge University Press, 111-138.

Bretherton, C. S., M. Widmann, V. P. Dymnikov, J. M. Wallace, and I. Blade, 1999: Effective number of degrees of freedom of a spatial field. J. Climate, 12, 1990-2009, https://doi.org/ 10.1175/1520-0442(1999)012<1990:TENOSD > 2.0.CO;2.

Czaja, A., and C. Frankignoul, 1999: Influence of the North Atlantic SST on the atmospheric circulation. Geophys. Res. Lett., 26, 2969-2972, https://doi.org/10.1029/1999GL900613.

Dee, D., and Coauthors, 2011: The ERA-Interim reanalysis: Configuration and performance of the data assimilation system. Quart. J. Roy. Meteor. Soc., 137, 553-597, https://doi.org/ 10.1002/qj.828.

Diedhiou, A., S. Janicot, A. Viltard, and P. de Felice, 1998: Evidence of two regimes of easterly wave over West Africa and the tropical Atlantic. Geophys. Res. Lett., 25, 2805-2808, https://doi.org/10.1029/98GL02152.

Fontaine, B., J. Garcia-Serrano, P. Roucou, B. RodriguezFonseca, T. Losada, F. Chauvin, and S. Janicot, 2010: Impacts of warm and cold situations in the Mediterranean basins on the West African monsoon: Observed connection patterns (1979-2006) and climate simulations. Climate Dyn., 35, 95-114, https://doi.org/10.1007/ s00382-009-0599-3.

Funk, C. C., and Coauthors, 2014: A quasi-global precipitation time series for drought monitoring. USGS Data Series 832, 4 pp., https://doi.org/10.3133/ds832.

- , A. Verdin, J. Michaelsen, P. Peterson, D. Pedreros, and G. Husak, 2015: A global satellite-assisted precipitation climatology. Earth Syst. Sci. Data, 7, 275-287, https://doi.org/ 10.5194/essd-7-275-2015.

Gaetani, M., B. Fontaine, P. Roucou, and M. Baldi, 2010: Influence of the Mediterranean Sea on the West African monsoon: Intraseasonal variability in numerical simulations. J. Geophys. Res., 115, D24115, https://doi.org/10.1029/ 2010JD014436. 
Giannini, A., R. Saravanan, and P. Chang, 2003: Oceanic forcing of Sahel rainfall on interannual to interdecadal time scales. Science, 302, 1027-1030, https://doi.org/10.1126/science.1089357.

— - S. Salack, T. Lodoun, A. Ali, A. T. Gaye, and O. Ndiaye, 2013: Unifying view of climate change in the Sahel linking intra-seasonal, interannual and longer time scales. Environ. Res. Lett., 8, 024010, https://doi.org/10.1088/1748-9326/8/ $2 / 024010$

Gómara, I., E. Mohino, T. Losada, M. Dominguez, R. SuarezMoreno, and B. Rodriguez-Fonseca, 2018: Impact of dynamical regionalization on precipitation biases and teleconnections over West Africa. Climate Dyn., 50, 4481-4506, https://doi.org/ 10.1007/s00382-017-3886-4.

Hill, S. A., Y. Ming, I. M. Held, and M. Zhao, 2017: A moist static energy budget-based analysis of the Sahel rainfall response to uniform oceanic warming. J. Climate, 30, 5637-5660, https:// doi.org/10.1175/JCLI-D-16-0785.1.

Janicot, S., S. Trzaska, and I. Poccard, 2001: Summer Sahel-ENSO teleconnection and decadal time scale SST variations. Climate Dyn., 18, 303-320, https://doi.org/10.1007/s003820100172.

Joly, M., and A. Voldoire, 2009: Influence of ENSO on the West African monsoon: Temporal aspects and atmospheric processes. J. Climate, 22, 3193-3210, https://doi.org/10.1175/ 2008JCLI2450.1.

Katz, R. W., and B. G. Brown, 1992: Extreme events in a changing climate: Variability is more important than averages. Climatic Change, 21, 289-302, https://doi.org/10.1007/BF00139728.

Lintner, B. R., and J. C. H. Chiang, 2007: Adjustment of the remote tropical climate to El Niño conditions. J. Climate, 20, 2544-2557, https://doi.org/10.1175/JCLI4138.1.

Lobell, D. B., M. Bänziger, C. Magorokosho, and B. Vivek, 2011: Nonlinear heat effects on African maize as evidenced by historical yield trials. Nat. Climate Change, 1, 42-45, https://doi.org/ 10.1038/nclimate1043.

Losada, T., B. Rodríguez-Fonseca, S. Janicot, S. Gervois, F. Chauvin, and P. Ruti, 2010: A multi-model approach to the Atlantic equatorial mode: Impact on the West African monsoon. Climate Dyn., 35, 29-43, https://doi.org/10.1007/ s00382-009-0625-5.

Ly, M., S. B. Traore, A. Agali, and B. Sarr, 2013: Evolution of some observed climate extremes in the West African Sahel. Wea. Climate Extremes, 1, 19-25, https://doi.org/ 10.1016/j.wace.2013.07.005.

Martin, E. R., and C. D. Thorncroft, 2014: The impact of the AMO on the West African monsoon annual cycle. Quart. J. Roy. Meteor. Soc., 140, 31-46, https://doi.org/10.1002/qj.2107.

$\longrightarrow$, and - 2015: Representation of African easterly waves in CMIP5 models. J. Climate, 28, 7702-7715, https://doi.org/ 10.1175/JCLI-D-15-0145.1.

Mitchell, J. F. B., S. Manabe, V. Meleshko, and T. Tokioka, 1990: Equilibrium climate change and its implications for the future. Climate Change: The IPCC Scientific Assessment, J. T. Houghton, G. J. Jenkins, and J. J. Ephraums, Eds., Cambridge University Press, 131-172.

Mohino, E., B. Rodríguez-Fonseca, T. Losada, S. Gervois, S. Janicot, J. Bader, P. Ruti, and F. Chauvin, 2011a: Changes in the interannual SST-forced signals on West African rainfall. AGCM intercomparison. Climate Dyn., 37, 1707-1725, https:// doi.org/10.1007/s00382-011-1093-2.

, — C. R. Mechoso, S. Gervois, P. Ruti, and F. Chauvin, 2011b: Impacts of the tropical Pacific/Indian Oceans on the seasonal cycle of the West African monsoon. J. Climate, 24, 3878-3891, https://doi.org/10.1175/2011JCLI3988.1.
New, M., and Coauthors, 2006: Evidence of trends in daily climate extremes over southern and west Africa. J. Geophys. Res., 111, D14102, https://doi.org/10.1029/2005JD006289.

Okonkwo, C., 2014: An advanced review of the relationships between Sahel precipitation and climate indices: A wavelet approach. Int. J. Atmos. Sci., 2014, 759067, https://doi.org/ 10.1155/2014/759067.

Okumura, Y., S. P. Xie, A. Numaguti, and Y. Tanimoto, 2001: Tropical Atlantic air-sea interaction and its influence on the NAO. Geophys. Res. Lett., 28, 1507-1510, https://doi.org/ 10.1029/2000GL012565.

Parhi, P., A. Giannini, P. Gentine, and U. Lall, 2016: Resolving contrasting regional rainfall responses to El Niño over tropical Africa. J. Climate, 29, 1461-1476, https://doi.org/ 10.1175/JCLI-D-15-0071.1.

Park, J., J. Bader, and D. Matei, 2016: Anthropogenic Mediterranean warming essential driver for present and future Sahel rainfall. Nat. Climate Change, 6, 941-945, https://doi.org/10.1038/nclimate3065.

Peyrillé, P., J.-P. Lafore, and J.-L. Redelsperger, 2007: An idealized two-dimensional framework to study the West African monsoon. Part I: Validation and key controlling factors. J. Atmos. Sci., 64, 2765-2782, https://doi.org/10.1175/JAS3919.1.

Rayner, N. A., D. E. Parker, E. B. Horton, C. K. Folland, L. V. Alexander, D. P. Rowell, E. C. Kent, and A. Kaplan, 2003: Global analyses of sea surface temperature, sea ice, and night marine air temperature since the late nineteenth century. J. Geophys. Res., 108, 4407, https://doi.org/10.1029/2002JD002670.

Rodríguez-Fonseca, B., I. Polo, J. García-Serrano, T. Losada, E. Mohino, C. R. Mechoso, and F. Kucharski, 2009: Are Atlantic Niños enhancing Pacific ENSO events in recent decades? Geophys. Res. Lett., 36, L20705, https://doi.org/ 10.1029/2009GL040048.

and Coauthors, 2011: Interannual and decadal SST-forced responses of the West African monsoon. Atmos. Sci. Lett., 12, 67-74, https://doi.org/10.1002/asl.308.

, and Coauthors, 2015: Variability and predictability of West African droughts: A review on the role of sea surface temperature anomalies. J. Climate, 28, 4034-4060, https://doi.org/ 10.1175/JCLI-D-14-00130.1.

Rowell, D. P., 2001: Teleconnections between the tropical Pacific and the Sahel. Quart. J. Roy. Meteor. Soc., 127, 1683-1706, https://doi.org/10.1002/qj.49712757512.

_ 2013: Simulating SST teleconnections to Africa: What is the state of the art? J. Climate, 26, 5397-5418, https://doi.org/ 10.1175/JCLI-D-12-00761.1.

Salack, S., A. Giannini, M. Diakhaté, A. T. Gaye, and B. Muller, 2014: Oceanic influence on the subseasonal to interannual timing and frequency of extreme dry spells over the West African Sahel. Climate Dyn., 42, 189-201, https://doi.org/ 10.1007/s00382-013-1673-4.

Sané, O., A. T. Gaye, M. Diakhaté, and M. Aziadekey, 2015: Social vulnerability assessment to flood in Medina Gounass Dakar. J. Geogr. Inf. Syst., 7, 58838, https://doi.org/10.4236/jgis.2015.74033.

,,--- , and -2016 : Critical factors of vulnerability that enable Medina Gounass (Dakar/Senegal) to adapt against seasonal flood events. J. Geogr. Inf. Syst., 8, 457-469, https:// doi.org/10.4236/jgis.2016.84038.

Sheen, K. L., D. Smith, N. Dunstone, R. Eade, D. Rowell, and M. Vellinga, 2017: Skilful prediction of Sahel summer rainfall on inter-annual and multi-year timescales. Nat. Commun., 8, 14966, https://doi.org/10.1038/ncomms14966.

Skinner, C. B., and N. S. Diffenbaugh, 2013: The contribution of African easterly waves to monsoon precipitation in the CMIP3 
ensemble. J. Geophys. Res. Atmos., 118, 3590-3609, https:// doi.org/10.1002/jgrd.50363.

Suárez-Moreno, R., B. Rodríguez-Fonseca, J. A. Barroso, and A. H. Fink, 2018: Interdecadal changes in the leading ocean forcing of Sahelian rainfall interannual variability: Atmospheric dynamics and role of multidecadal SST background. J. Climate, 31, 6687-6710, https://doi.org/10.1175/JCLI-D-17-0367.1.

Ta, S., K. Y. Kouadio, K. E. Ali, E. Toualy, A. Aman, and F. Yoroba, 2016: West Africa extreme rainfall events and large-scale ocean surface and atmospheric conditions in the tropical Atlantic. Adv. Meteor., 2016, 1940456, https://doi.org/ 10.1155/2016/1940456.

Taylor, C. M., and Coauthors, 2017: Frequency of extreme Sahelian storms tripled since 1982 in satellite observations. Nature, $\mathbf{5 4 4}$, 475-478, https://doi.org/10.1038/nature22069. ter Braak, C. J. F., and S. Juggins, 1993: Weighted averaging partial least squares regression (WA-PLS): An improved method for reconstructing environmental variables from species assemblages. Hydrobiologia, 269-270, 485-502, https://doi.org/ 10.1007/BF00028046.

Torri, G., Z. Kuang, and Y. Tian, 2015: Mechanisms for convection triggering by cold pools. Geophys. Res. Lett., 42, 1943-1950, https://doi.org/10.1002/2015GL063227.

von Storch, H., and F. W. Zwiers, 1999: Statistical Analysis in Climate Research. Cambridge University Press, 484 pp.

Wei, N., Y. Dai, M. Zhang, L. Zhou, D. Ji, S. Zhu, and L. Wang, 2014: Impact of precipitation-induced sensible heat on the simulation of land-surface air temperature. J. Adv. Model. Earth Syst., 6, 1311-1320, https://doi.org/10.1002/ 2014MS000322. 